(c) American Dairy Science Association, 2006.

\title{
Induction of Interleukin-12 by Lactobacillus Strains Having a Rigid Cell Wall Resistant to Intracellular Digestion
}

\author{
K. Shida, ${ }^{1}$ J. Kiyoshima-Shibata, M. Nagaoka, K. Watanabe, and M. Nanno \\ Yakult Central Institute for Microbiological Research, 1796 Yaho, Kunitachi, Tokyo 186-8650, Japan
}

\begin{abstract}
Some strains of lactobacilli can stimulate macrophages and dendritic cells to secrete IL-12, which plays a key role in activating innate immunity. We examined the IL-12-inducing ability of 47 Lactobacillus strains belonging to 10 species in mouse peritoneal macrophages, and characterized the properties important for the induction of IL-12. Although considerable differences in IL-12-inducing ability were observed among the strains tested, almost all strains belonging to the Lactobacillus casei group (L. casei, Lactobacillus rhamnosus, and Lactobacillus zeae) or to Lactobacillus fermentum induced high levels of IL-12. Phagocytosis of lactobacilli was necessary for IL-12 induction, and the strains with strong IL-12 induction were relatively resistant to lysis in the macrophages. The sensitivity of Lactobacillus strains to in vitro treatment with M-1 enzyme, a member of the $N$-acetylmuramidases, was negatively correlated with IL-12-inducing ability. Using a probiotic strain, $L$. casei strain Shirota (LcS), we showed that the cell wall of LcS could be digested by long-term treatment with a high dose of M-1 enzyme and that the IL-12-inducing ability was diminished according to the duration of the enzyme treatment. The soluble polysaccharide-peptidoglycan complex released from the cell wall of LcS did not induce IL-12, whereas the insoluble intact cell wall of LcS induced IL-12. These results suggest that the intact cell wall structure of lactobacilli is an important element in the ability to induce IL-12 and that Lactobacillus strains having a rigid cell wall resistant to intracellular digestion effectively stimulate macrophages to induce IL-12.
\end{abstract}

Key words: interleukin-12, lactobacilli, phagocytosis, lysis

\section{INTRODUCTION}

Lactobacilli are one of the major constituents of normal human indigenous flora and are believed to play

Received December 12, 2005.

Accepted March 27, 2006.

${ }^{1}$ Corresponding author: kan-shida@yakult.co.jp important roles in the development and maintenance of both the mucosal and systemic immune system of the host (Björkstén, 1999). These gram-positive lactic acid bacteria have long been used in the preparation of fermented foods such as yogurt, cheese, and fermented vegetables and meats. Recently, much attention has been paid to the beneficial functions of lactobacilli in addition to their importance in the preparation process of fermented foods. Lactobacilli and bifidobacteria are now the bacteria most often used as probiotics, which are defined as live microbial food ingredients that are beneficial to human health (Salminen et al., 1998). Among several health-promoting effects of probiotic lactobacilli, immunoregulatory functions have been studied with great interest (Dugas et al., 1999; Reid et al., 2003). Some specific strains of probiotic lactobacilli were recently shown to exhibit antitumor and anti-infectious activity through activation of innate immunity, such as augmentation of the functions of macrophages and NK cells (Kato, 2000; Perdigón et al., 2001). Some probiotics have antiallergic activity, which may be explained by regulation of the Thelper (Th)1-Th2 balance (Shida et al., 2002; Kalliomäki and Isolauri, 2004).

Interleukin-12 is well known to play a critical role both in inducing a Th1-dominant immune response and in enhancing cellular immunity (Trinchieri, 1994). Many researchers have discussed the importance of IL12 induced by lactobacilli in relation to their immunoregulatory functions. We have clearly documented that Lactobacillus casei strain Shirota (LcS) can promote the development of Th1 cells from naïve CD4-positive $\mathrm{T}$ cells through secretion of IL-12 by macrophages (Shida et al., 1998). Some studies have shown that neutralization of IL-12 with monoclonal antibodies can at least partially reduce the immunoregulatory activity of lactobacilli (Yasutake et al., 1999; Shida et al., 2002). Therefore, IL-12 is considered to play key roles in the functions of probiotics, especially in enhancing the Th1 response and cellular immunity. Accordingly, the ability of a strain to induce IL-12 could be a critical index of immunostimulatory activity.

Although studies comparing the IL-12-inducing ability of Lactobacillus strains have shown that some specific strains belonging to the species of $L$. casei-Lactoba- 
cillus paracasei and Lactobacillus rhamnosus are potent IL-12 inducers (Miettinen et al., 1998; Hessle et al., 1999; Christensen et al., 2002), it has not been clear why these specific strains can strongly induce IL-12. Little information has been available on the active components or structures in lactobacilli or on the properties important for IL-12 induction. Active components have previously been revealed from other bacteria that induce IL-12 secretion. Lipopolysaccharide (Salkowski et al., 1997) from gram-negative bacteria, lipoarabinomannan (Yoshida and Koide, 1997) from mycobacteria, lipoteichoic acid (Cleveland et al., 1996) from grampositive bacteria, and bacterial lipopeptide (Thoma-Uszynski et al., 2000) and unmethylated CpG DNA (Halpern et al., 1996) have been reported to induce IL-12. These bacterial components are recognized by corresponding Toll-like receptors (TLR), followed by cytokine secretion (Takeda and Akira, 2005). On the other hand, researchers have often observed that the ability of these soluble bacterial components to induce IL-12 is not particularly strong compared with preparations of intact bacterial cells (Cleveland et al., 1996; Huang et al., 1999; Hessle et al., 2000). Underhill et al. (1999) showed that phagocytosis of bacteria elicits recruitment of TLR to phagosomes to recognize bacterial components effectively, and that bacterial phagocytosis and subsequent recognition of TLR cooperate to induce proinflammatory cytokines. This may be why soluble bacterial components show weaker induction of IL-12 than do intact bacterial cell preparations. Thus, further studies investigating the active components or structures of bacteria responsible for IL-12 induction should focus on the interaction between whole bacterial cells and phagocytic cells, in addition to that between bacterial cell components and their receptors on phagocytic cells, considering the importance of bacterial phagocytosis.

In this study, we examined the phagocytosis and lysis of lactobacilli by macrophages and evaluated properties related to the IL-12-inducing ability of lactobacilli. The results obtained indicate the importance of a rigid cell wall structure resistant to intracellular digestion in the effective induction of IL-12.

\section{MATERIALS AND METHODS}

\section{Reagents and Culture Medium}

Lysozyme from egg white, trypsin, and cytochalasin $\mathrm{D}$ were purchased from Sigma (St. Louis, MO). The M1 enzyme ( $N$-acetylmuramidase SG) from Streptomyces globisporus was obtained from Seikagaku Corp. (Tokyo, Japan), Benzon nuclease was from Merck (Darmstadt, Germany); and DNase, RNase, and pronase were from Roche Diagnostics (Indianapolis, IN). Roswell Park Memorial Institute (RPMI) 1640 medium (Sigma), supple- mented with $10 \%$ heat-inactivated fetal calf serum, 100 $\mathrm{U} / \mathrm{mL}$ of penicillin, and $100 \mu \mathrm{g} / \mathrm{mL}$ of streptomycin, was used to culture macrophages.

\section{Animals}

Female BALB/c mice and male C57BL/6 mice were purchased from Japan SLC (Shizuoka, Japan). Male MyD88-, TLR2-, and TLR4-deficient mice with a C57BL/6 genetic background were obtained from Oriental Bioservice (Kyoto, Japan). Animals were used at 8 to $11 \mathrm{wk}$ of age. Experiments were performed in accordance with the guidelines for the care and use of laboratory animals of the Yakult Central Institute (Tokyo, Japan).

\section{Bacteria}

The Lactobacillus strains used in this study are summarized in Table 1. A probiotic strain, LcS, was originally isolated from healthy human intestine at the Yakult Central Institute, based on acid and bile tolerance and survival in the gastrointestinal passage. The other bacteria were initially obtained from the American Type Culture Collection (ATCC, Rockville, MD), the Deutsche Sammlung von Mikroorganismen und Zellkulturen GmbH (DSM, Braunschweig, Germany), the Japan Collection of Microorganisms (JCM, Wako, Japan), the National Collection of Dairy Organisms (NCDO, Reading, UK), the National Collection of Food Bacteria (NCFB, Reading, UK), the National Collection of Industrial, Food and Marine Bacteria (NCIMB, Aberdeen, UK), the National Institute for Research in Dairying (NIRD, Reading, UK), and the Nodai Research Institute Culture Collection (NRIC, Tokyo, Japan). These bacteria were renumbered as YIT (Yakult Institute, Tokyo) strains at the Yakult Central Institute. Preparation of heat-killed bacteria has been described elsewhere (Shida et al., 1998). In brief, the bacteria were cultured at $37^{\circ} \mathrm{C}$ for $20 \mathrm{~h}$ in lactobacilli-MRS broth (Difco, Detroit, MI), washed with sterile distilled water, heated at $100^{\circ} \mathrm{C}$ for $30 \mathrm{~min}$, and then lyophilized.

Fluorescein isothiocyanate (FITC)-labeled lactobacilli were prepared with FITC isomer-I (Dojindo Lab., Kumamoto, Japan). Heat-killed lactobacilli were suspended at a concentration of $5 \mathrm{mg} / \mathrm{mL}$ in $50 \mathrm{~m} M$ carbonate buffer ( $\mathrm{pH} 9.6)$, reacted with FITC isomer-I ( $4.5 \mu \mathrm{g} /$ $\mathrm{mL})$ at $37^{\circ} \mathrm{C}$ for $60 \mathrm{~min}$, and then washed with sterile PBS.

\section{Preparation of Cell Components}

Bacterial cell components were prepared from heatkilled LcS. Isolation of the protoplast and the polysac- 
Table 1. Lactobacillus strains used in this study

\begin{tabular}{|c|c|}
\hline Species & Strains $^{1}$ \\
\hline L. acidophilus & $\begin{array}{l}\text { YIT } 0070^{\mathrm{T}} \text { (ATCC 4356), YIT } 0198 \text { (JCM 1028), YIT } 0200 \text { (JCM 1229), YIT } 0281 \text { (ATCC 4796), } \\
\text { YIT } 0283 \text { (NCFB 104) }\end{array}$ \\
\hline L. casei & $\begin{array}{l}\text { YIT } 0007 \text { (JCM 1109), YIT 0180 (ATCC 334), YIT } 0209 \text { (NCDO 151), YIT } 0210 \text { (ATCC 25599), } \\
\text { YIT } 0262 \text { (JCM 1181), strain Shirota }\end{array}$ \\
\hline L. delbrueckii ssp. bulgaricus & $\begin{array}{l}\text { YIT } 0181^{\mathrm{T}} \text { (ATCC 11842), YIT } 0459 \text { (NCIMB 701006), YIT } 0463 \text { (NCIMB 702074), } \\
\text { YIT } 0474 \text { (NCIMB 702487), YIT } 0475 \text { (NCIMB 702488) }\end{array}$ \\
\hline L. fermentum & YIT 0079 (ATCC 11739), YIT 0081 ${ }^{\mathrm{T}}$ (ATCC 14931), YIT 0082 (ATCC 14932), YIT 0129 (ATCC 9338) \\
\hline L. johnsonii & $\begin{array}{l}\text { YIT } 0074 \text { (ATCC 11506), YIT } 0201 \text { (JCM 1017), YIT } 0202 \text { (JCM 1022), YIT 0219T (JCM 2012), } \\
\text { YIT } 0284 \text { (NCFB 1060) }\end{array}$ \\
\hline L. plantarum & $\begin{array}{l}\text { YIT } 0101 \text { (ATCC 8014), YIT 0102 }{ }^{\mathrm{T}} \text { (ATCC 14917), YIT } 0103 \text { (ATCC 10241), YIT } 0220 \text { (ATCC 14431), } \\
\text { YIT } 10015 \text { (NRIC 1591) }\end{array}$ \\
\hline L. rhamnosus & $\begin{array}{l}\text { YIT 0105 (ATCC 7469), YIT } 0124 \text { (ATCC 9595), YIT } 0125 \text { (ATCC 11981), YIT } 0126 \text { (ATCC 11982), } \\
\text { YIT } 0232 \text { (ATCC 53103) }\end{array}$ \\
\hline
\end{tabular}

${ }^{1}$ Original strain numbers are in parentheses. A superscript $\mathrm{T}\left({ }^{\mathrm{T}}\right)$ indicates a type strain. YIT = Yakult Institute, Tokyo $($ Tokyo, Japan); ATCC = American Type Culture Collection (Rockville, MD); JCM = Japan Collection of Microorganisms (Wako, Japan); NCFB = National Collection of Food Bacteria (Reading, UK); NCDO = National Collection of Dairy Organisms (Reading, UK); NCIMB = National Collection of Industrial, Food and Marine Bacteria (Aberdeen, UK); DSM = Deutsche Sammlung von Mikroorganismen und Zellkulturen GmbH (Braunschweig, Germany); NIRD = National Institute for Research in Dairying (Reading, UK); NIRC = Nodai Research Institute Culture Collection (Tokyo, Japan).

charide-peptidoglycan complex (PS-PG) was described previously (Nagaoka et al., 1990; Matsuguchi et al., 2003). In brief, heat-killed LcS was exhaustively digested with M-1 enzyme for $16 \mathrm{~h}$. After centrifugation, the precipitate was washed with distilled water and then collected as the protoplast. The supernatant was treated with DNase, RNase, and trypsin. The digest was dialyzed against distilled water, lyophilized, and used as PS-PG. Intact cell wall (ICW) was prepared as described elsewhere (Matsuguchi et al., 2003). Briefly, heat-killed cells were suspended in $0.3 \%$ SDS solution and boiled for $15 \mathrm{~min}$. After centrifugation, the precipitate was washed with acetone. The cells were treated with pronase and delipidated by successive refluxing with methanol, methanol-chloroform-water (1:1:1), and methanol-chloroform (1:1). The delipidated materials were treated with Benzon nuclease and pronase. The insoluble material was washed with distilled water, lyophilized, and then used as ICW. To release the polysaccharide moiety from the linkage region of ICW, the ICW was treated with $47 \%$ hydrogen fluoride at $4^{\circ} \mathrm{C}$ for $20 \mathrm{~h}$ (Mort and Lamport, 1977). Hydrogen fluoridetreated ICW (HF-ICW) was washed with deionized water and lyophilized.

\section{Isolation of Peritoneal Macrophages and Culture}

Peritoneal macrophages were isolated from BALB/c mice, unless indicated otherwise. Mice were injected intraperitoneally with $2 \mathrm{~mL}$ of $4 \%$ thioglycollate. After $4 \mathrm{~d}$, peritoneal exudate cells were isolated as macro- phages by washing the peritoneal cavity with Hanks' balanced salt solution containing $10 \mathrm{~m} M$ HEPES. Peritoneal macrophages $\left(2 \times 10^{5}\right.$ cells $)$ were cultured with heat-killed bacteria $(0.1$ to $100 \mu \mathrm{g} / \mathrm{mL})$ in $200 \mu \mathrm{L}$ of RPMI 1640 medium in a 96 -well culture plate. Supernatants were collected at $24 \mathrm{~h}$ for determination of IL12 p70 and IL-10. To examine the importance of bacterial phagocytosis, cytochalasin $\mathrm{D}(5 \mu \mathrm{g} / \mathrm{mL})$ was added $30 \mathrm{~min}$ before stimulation with bacteria $(10 \mu \mathrm{g} / \mathrm{mL}$; Shibata, 1995).

\section{Microscopic Analysis of Phagocytosis}

Peritoneal macrophages $\left(2 \times 10^{5}\right.$ cells $)$ were plated on round 12-mm collagen type I-coated cover glasses (Asahi Techno Glass, Tokyo, Japan) in a 24-well culture plate in $2 \mathrm{~mL}$ of RPMI 1640 medium. After preincubation for $16 \mathrm{~h}$, bacteria were added at $10 \mu \mathrm{g} / \mathrm{mL}$. The macrophages were harvested after 4 and $24 \mathrm{~h}$ cultures, washed with PBS, fixed with methanol for $10 \mathrm{~min}$, and then stained with Giemsa. The phagocytosis of bacteria by macrophages was observed by light microscopy.

\section{Flow Cytometric Analysis of Phagocytosis}

Peritoneal macrophages $\left(1 \times 10^{6}\right.$ cells $)$ were cultured with FITC-labeled lactobacilli $(10 \mu \mathrm{g} / \mathrm{mL})$ in $2 \mathrm{~mL}$ of RPMI 1640 medium in a 24-well culture plate for 2, 4,8 , and $24 \mathrm{~h}$. The macrophages were dislodged by treatment with $10 \mathrm{~m} M$ EDTA-PBS for $10 \mathrm{~min}$, washed with $3 \mathrm{~m} M$ EDTA-PBS, and then suspended in $1.5 \mathrm{~m} M$ 
EDTA-1.25\% formalin-PBS. Analysis was performed on an EPICS Altra flow cytometer with Expo32 software (Beckman Coulter, Miami, FL).

\section{N-Acetylmuramidase Treatment}

To evaluate the sensitivity of bacteria to $N$-acetylmuramidase, heat-killed bacteria suspended at $2 \mathrm{mg} /$ $\mathrm{mL}$ in $50 \mathrm{mM}$ Tris-maleate buffer ( $\mathrm{pH}$ 7.0) containing $4 \mathrm{mM} \mathrm{MgCl} 2$ were treated with lysozyme $(50 \mu \mathrm{g} / \mathrm{mL})$ for $120 \mathrm{~min}$ or with M-1 enzyme $(10 \mu \mathrm{g} / \mathrm{mL})$ for 10 min. After denaturing the enzymes by heat treatment $\left(100^{\circ} \mathrm{C}, 5 \mathrm{~min}\right), 10 \%$ SDS solution was added to the reaction mixtures at a final concentration of $2 \%$, and the mixture was stirred vigorously to dissolve protoplasts resulting from digestion of the cell wall. Optical density at $600 \mathrm{~nm}(\mathbf{O D 6 0 0})$ was measured. Sensitivity of bacteria to the enzymes was calculated using the following formula:

$$
\begin{gathered}
\text { sensitivity }(\%)=\left(\mathrm{OD} 600_{0 \min }-\mathrm{OD} 600_{\text {treated }}\right) / \\
\mathrm{OD} 600_{0 \min } \times 100
\end{gathered}
$$

To prepare LcS with cell wall structures at levels of various degradation, heat-killed $\mathrm{LcS}$ was treated with $50 \mu \mathrm{g} / \mathrm{mL}$ of M-1 enzyme for $10,30,60$, or $120 \mathrm{~min}$. Enzyme-treated LcS was washed 3 times with sterile PBS before addition to the cell cultures. The extent of lysis of the cell wall was evaluated on the basis of the reduction of OD600 after SDS treatment, as described above. Cell wall degradation was also confirmed by microscopic analysis after Giemsa staining, which showed that the color of cells had changed from blue to red.

\section{ELISA for Cytokines}

Determination of IL-12p70 and IL-10 levels in culture supernatants was performed by sandwich ELISA. Rat antimouse IL-12 (clone 9A5) and IL-10 (clone JES5SXC1) monoclonal antibodies were used as the capture antibodies, and biotinylated rat antimouse IL-12 (clone C17.8) and IL-10 (clone JES5-2A5) monoclonal antibodies, respectively, were used as the detection antibodies. These antibodies and recombinant mouse IL-12 and IL10 were purchased from BD Pharmingen (San Diego, $\mathrm{CA})$.

\section{RESULTS}

\section{IL-12-Inducing Ability of Lactobacillus Type Strains and LCS}

Mouse peritoneal macrophages were cultured with 10 type strains of common Lactobacillus species or a probiotic strain, LcS, for $24 \mathrm{~h}$, and the concentrations of IL-12 in the supernatants were measured. Considerable differences in IL-12-inducing ability were observed among the strains (Figure 1). Lactobacillus casei strain Shirota and the type strains of L. casei, L. rhamnosus, Lactobacillus zeae, and Lactobacillus fermentum induced high levels of IL-12, whereas Lactobacillus gasseri, Lactobacillus johnsonii, Lactobacillus acidophilus, Lactobacillus delbrueckii ssp. bulgaricus, Lactobacillus helveticus, and Lactobacillus plantarum induced very low levels of IL-12.

We also tested IL-10-inducing ability. Lactobacillus delbrueckii ssp. bulgaricus and L. plantarum, in addition to $L$. rhamnosus, $L$. zeae, and $L$. fermentum, were able to induce high levels of IL-10. Interestingly, the optimal bacterial doses that induced IL-12 and IL-10 were different in most Lactobacillus strains $(10 \mu \mathrm{g} / \mathrm{mL}$ for IL-12; $100 \mu \mathrm{g} / \mathrm{mL}$ for IL-10).

\section{Importance of Bacterial Phagocytosis and TLR Signaling in IL-12 Induction}

The phagocytosis of bacteria and the recognition of bacterial components by TLR are important in the effective induction of proinflammatory cytokines. We therefore examined whether the step of phagocytosing lactobacilli is critical in inducing IL-12 by using cytochalasin $\mathrm{D}$, an inhibitor of actin polymerization. The addition of cytochalasin $\mathrm{D}$ to macrophage cultures markedly diminished the IL-12-inducing ability of lactobacilli (Table 2), indicating that the phagocytosing step is important for IL-12 induction by lactobacilli.

Macrophages prepared from mice deficient in MyD88, an adapter molecule for TLR signaling, could not secrete IL-12 in response to LcS stimulation (Figure 2A). The lack of IL-12 induction was also observed when MyD88-deficient macrophages were cultured with the type strains of $L$. casei, L. rhamnosus, $L$. zeae, and $L$. fermentum (data not shown). These data suggest the essential role of TLR signaling in the induction of IL12. In contrast, macrophages deficient in either TLR2 or TLR4, as well as wild-type macrophages, secreted IL-12 in response to LcS stimulation (Figure 2B).

\section{Phagocytosis and Lysis of Lactobacilli by Macrophages}

Peritoneal macrophages were cultured with Lactobacillus strains for 4 and $24 \mathrm{~h}$ and then stained with Giemsa. The phagocytosis and lysis of lactobacilli by macrophages were observed by light microscopy. The pictures in Figure 3 indicate that the phagocytosis and lysis of lactobacilli could be divided into 3 patterns: group R (containing LcS and the type strains of L. casei, 


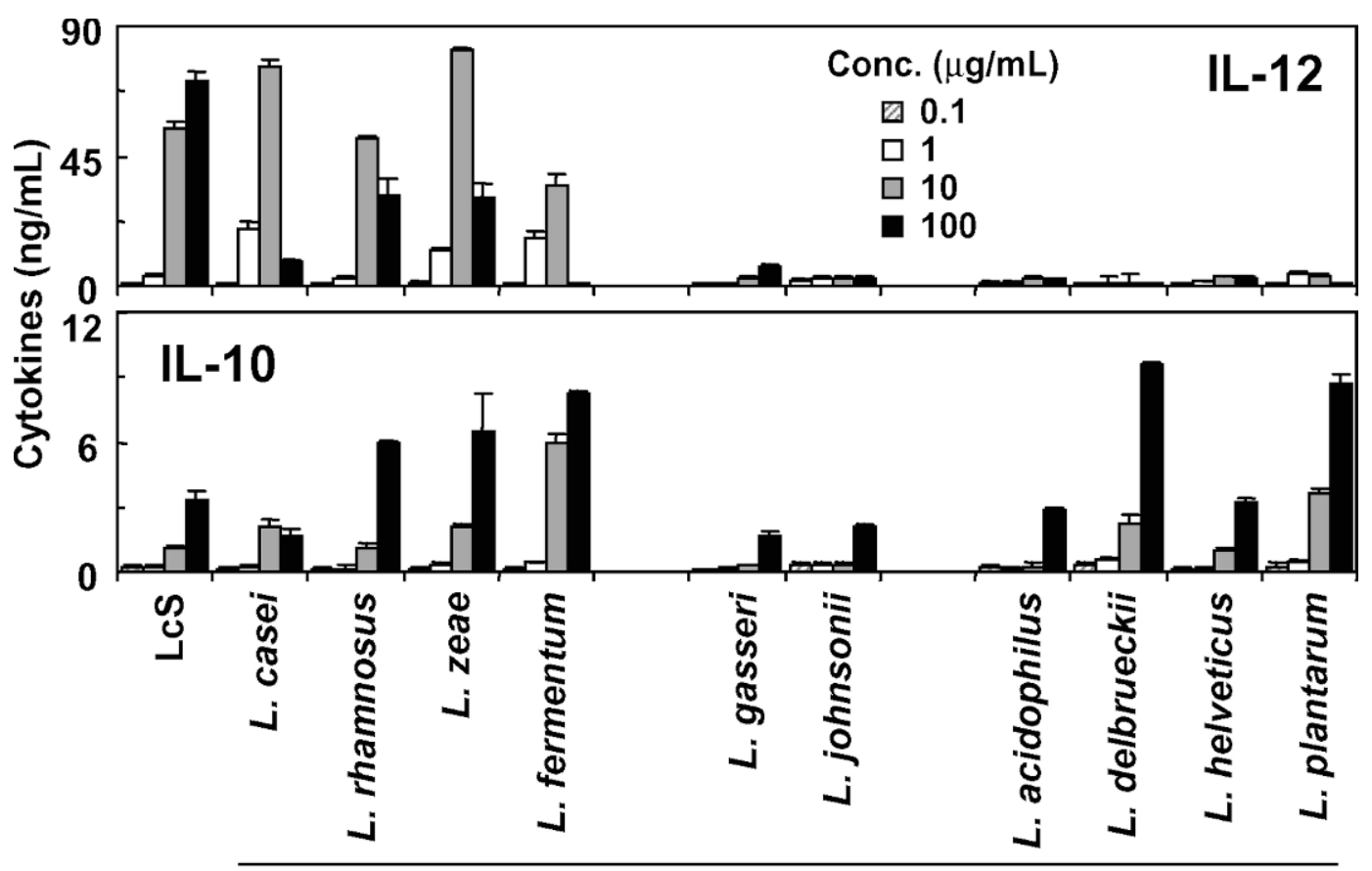

Type strains

Figure 1. Induction of IL-12 and IL-10 by Lactobacillus type strains and L. casei strain Shirota (LcS). Peritoneal macrophages were cultured with 10 type strains of Lactobacillus species or LcS $(0.1$ to $100 \mu \mathrm{g} / \mathrm{mL}$ ) for $24 \mathrm{~h}$, and the levels of IL-12 (top panel) and IL-10 (bottom panel) in culture supernatants were determined by ELISA. Data are means \pm SD of triplicate cultures.

L. rhamnosus, L. zeae, and L. fermentum), in which 24 $\mathrm{h}$ was required for the phagocytosis of large numbers of bacteria and in which phagocytosed bacteria maintained their morphology throughout this period; group $\mathrm{S}$ (containing L. acidophilus, L. delbrueckii ssp. bulgaricus, L. helveticus, and L. plantarum), in which less than $4 \mathrm{~h}$ was required for the phagocytosis of numerous bacteria, which were rapidly lysed in macrophages; and group I (containing $L$. gasseri and $L$. johnsonii), in which $24 \mathrm{~h}$ was required for the phagocytosis of many bacteria and in which phagocytosed bacteria were lysed. These results strongly suggest that phagocytosis of lac-

Table 2. Effect of cytochalasin D on IL-12 induction by lactobacilli ${ }^{1}$

\begin{tabular}{lcl}
\hline & \multicolumn{2}{c}{ IL-12, ng/mL } \\
\cline { 2 - 3 } Lactobacillus & Control & $\begin{array}{l}\text { With } \\
\text { cytochalasin D }\end{array}$ \\
\hline LcS & $79.3 \pm 5.7$ & $1.8 \pm 0.1$ \\
L. casei & $128.7 \pm 13.1$ & $1.3 \pm 0.2$ \\
L. rhamnosus & $75.7 \pm 8.9$ & $1.3 \pm 0.4$ \\
L. zeae & $112.4 \pm 10.2$ & $1.2 \pm 0.3$ \\
L. fermentum & $52.9 \pm 5.6$ & $1.8 \pm 0.2$ \\
\hline
\end{tabular}

${ }^{1}$ Peritoneal macrophages were cultured with L. casei strain Shirota (LcS) or type strains of Lactobacillus species in the absence (control) or presence of cytochalasin D for $24 \mathrm{~h}$, and the levels of IL-12 in culture supernatants were determined. tobacilli and their subsequent digestion are closely related to IL-12 induction.

Next, peritoneal macrophages were cultured with FITC-labeled L. casei (belonging to group R), L. john-
A

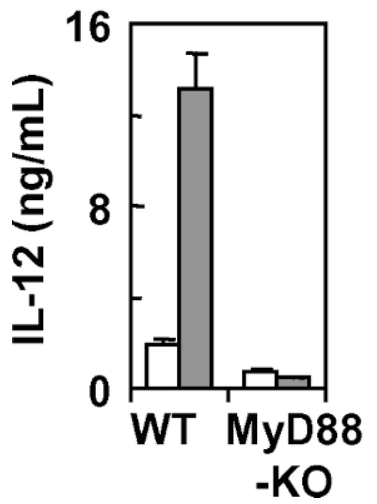

B

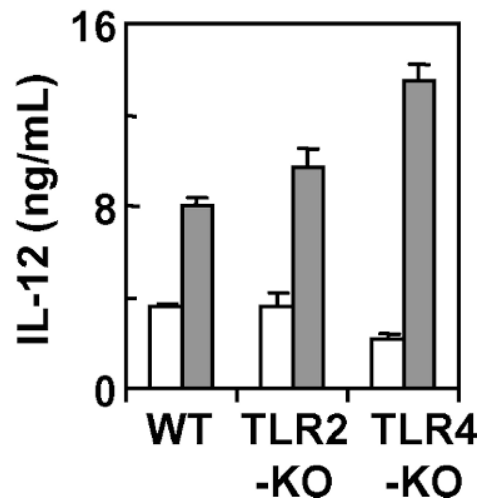

Figure 2. Importance of Toll-like receptor (TLR) signaling in IL12 induction by $L$. casei strain Shirota (LcS). (A) Macrophages from MyD88-deficient (MyD88-KO) or wild-type (WT) C57BL/6 mice were cultured with LcS (1 $\mu \mathrm{g} / \mathrm{mL}$, open bars; $10 \mu \mathrm{g} / \mathrm{mL}$, gray bars) for 24 h. (B) Macrophages from TLR2-deficient (TLR2-KO), TLR4-deficient (TLR4-KO), or WT C57BL/6 mice were cultured with LcS for $24 \mathrm{~h}$. The levels of IL-12 in culture supernatants were determined by ELISA. Data are means \pm SD of triplicate cultures. 


\section{Group R}

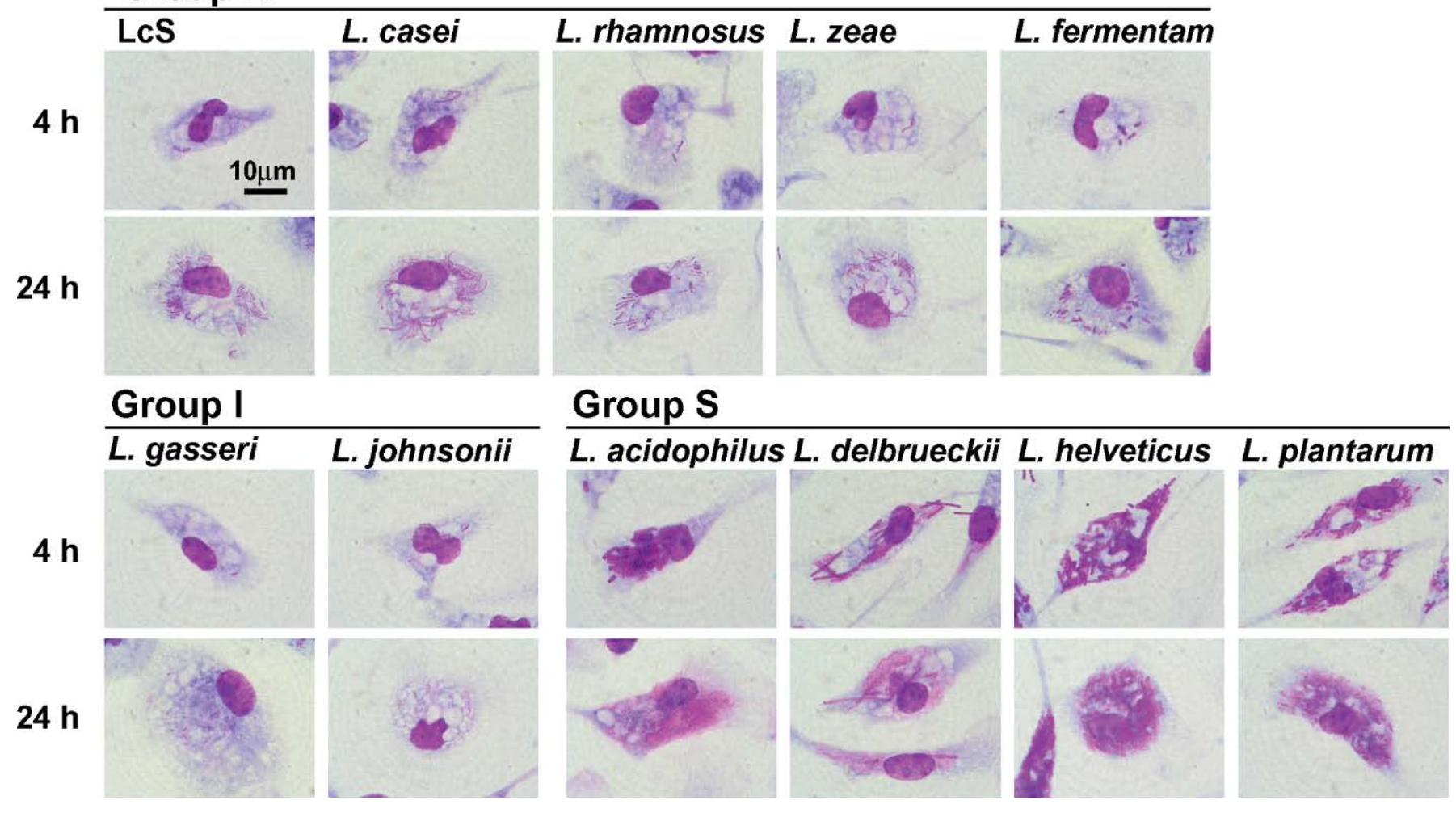

Figure 3. Microscopic analysis of phagocytosis and lysis of lactobacilli by macrophages. Peritoneal macrophages on collagen type I-coated cover glasses were cultured with 10 type strains of Lactobacillus species or L. casei strain Shirota (LcS; $10 \mu \mathrm{g} / \mathrm{mL})$ for 4 and $24 \mathrm{~h}$ and stained with Giemsa. Phagocytosis and lysis of bacteria by macrophages were observed by light microscopy.

sonii (belonging to group I), or L. plantarum (belonging to group S) for $2,4,8$, and $24 \mathrm{~h}$, and phagocytosis was analyzed by flow cytometry. The quantitative analysis indicated that $22 \%$ of macrophages phagocytosed $L$. case $i$ at $2 \mathrm{~h}$ of incubation, and the ratio of cells phagocytosing $L$. casei gradually increased and reached $66 \%$ at $24 \mathrm{~h}$ (Figure 4). In the case of $L$. johnsonii, the ratio of macrophages phagocytosing bacteria was $39 \%$ at $2 \mathrm{~h}$ and gradually increased until $8 \mathrm{~h}$ to $62 \%$. At $24 \mathrm{~h}$ of incubation, although most macrophages were considered to have phagocytosed bacteria, the intensity of fluorescence for those cells slightly decreased, probably because of decomposition of the FITC molecules. In $L$. plantarum, the ratio of macrophages phagocytosing bacteria had already reached $62 \%$ at $2 \mathrm{~h}$, and the intensity of fluorescence decreased slightly after $8 \mathrm{~h}$. The results obtained by flow cytometric analysis corresponded with those from the microscopic analysis shown in Figure 3.

\section{Sensitivity of Lactobacilli to In Vitro $\mathrm{N}$-Acetylmuramidase Treatment}

$N$-Acetylmuramidases play a critical role in digesting bacteria in phagolysosomes. To evaluate the lysis of lactobacilli quantitatively, we investigated the sensitivity of Lactobacillus strains to in vitro $N$-acetylmuramidase (lysozyme and M-1 enzyme) treatment. As shown in Figure 5, LcS and the type strains of $L$. casei, $L$. rhamnosus, L. zeae, L. fermentum, and L. gasseri showed strong resistance to treatment with both lysozyme and M-1 enzyme under the reaction conditions examined (lysozyme treatment: $50 \mu \mathrm{g} / \mathrm{mL}$ for $120 \mathrm{~min}$; M-1 enzyme treatment: $10 \mu \mathrm{g} / \mathrm{mL}$ for $10 \mathrm{~min})$. In contrast, $L$. acidophilus, $L$. delbrueckii ssp. bulgaricus, $L$. helveticus, and $L$. plantarum were sensitive to the enzymes. Lactobacillus johnsonii was sensitive to M-1 enzyme but resistant to lysozyme.

\section{Potent IL-12-Inducing Ability Is Conserved in Strains of the L. casei Group and in L. fermentum}

The IL-12-inducing ability of 36 additional reference strains was then investigated. As shown in Figure 6, 8 out of 9 strains belonging to $L$. casei, L. rhamnosus, or $L$. zeae induced high levels of IL-12, and all strains of these species were relatively resistant to M-1 enzyme treatment. Lactobacillus casei, L. rhamnosus, and $L$. zeae are closely related species in taxonomy and belong 
L. casei

$2 \mathrm{~h}$

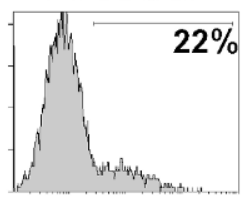

L. johnsonii L. plantarum
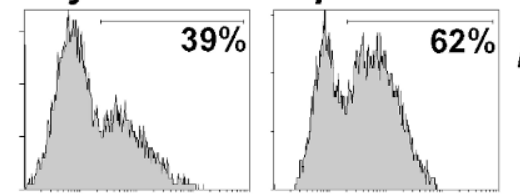

$4 \mathrm{~h}$
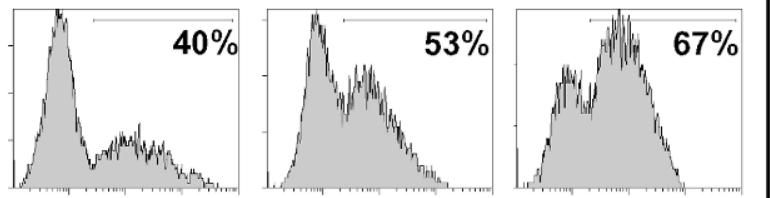

$8 \mathrm{~h}$
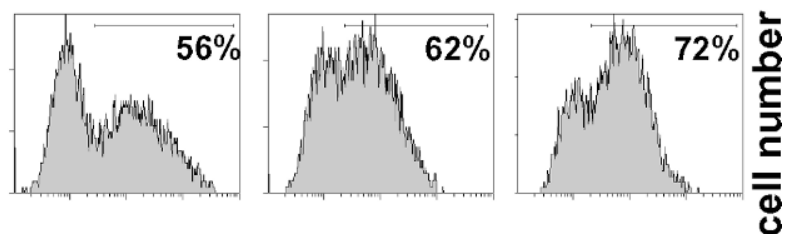

$24 \mathrm{~h}$
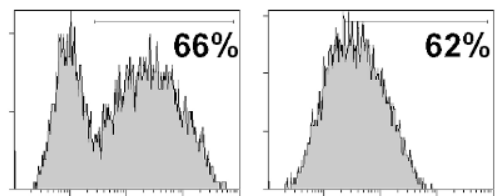

Fluorescence intensity

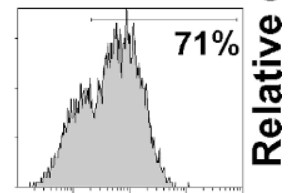

Figure 4. Flow cytometric analysis of phagocytosis of lactobacilli. Peritoneal macrophages were cultured with fluorescein isothiocyanate-labeled Lactobacillus type strains (10 $\mu \mathrm{g} / \mathrm{mL})$ for 2, 4, 8, and 24 $\mathrm{h}$ and then analyzed by flow cytometry. The percentage of fluorescence positive cells is shown.

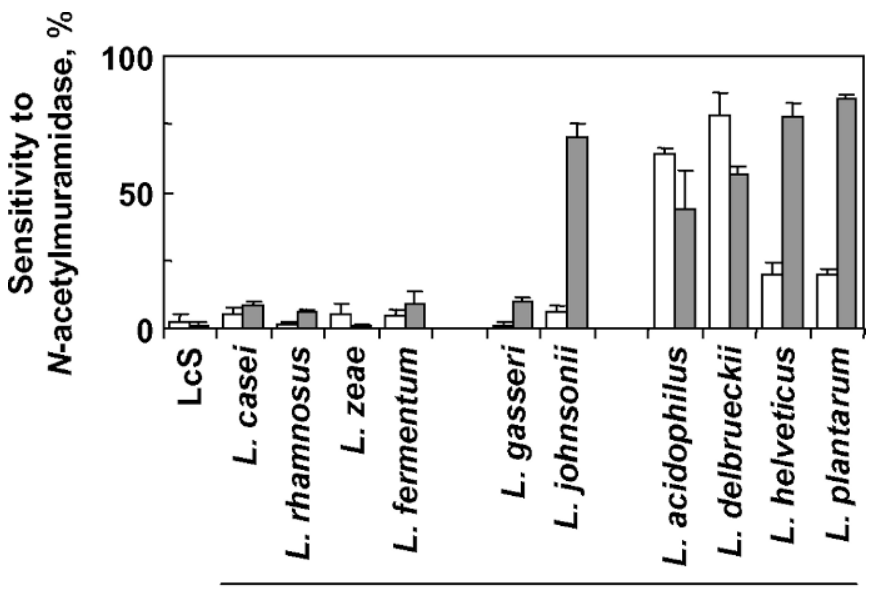

Type strains

Figure 5. Sensitivity to $N$-acetylmuramidase treatment of lactobacilli. Ten type strains of Lactobacillus species or L. casei strain Shirota $(\mathrm{LcS})$ were treated with lysozyme $(50 \mu \mathrm{g} / \mathrm{mL}$, open bars) for $120 \mathrm{~min}$ or M-1 enzyme (10 $\mu \mathrm{g} / \mathrm{mL}$, gray bars) for $10 \mathrm{~min}$. The sensitivity of bacteria to the enzymes was calculated as described in the Materials and Methods section. Data are means \pm SD of 3 independent experiments. to the $L$. casei group. An examination of the results for $\mathrm{LcS}$ and the type and reference strains of the $L$. casei group species (Figures 1 and 6 ) revealed that 12 out of 13 strains belonging to this group were potent IL-12 inducers, suggesting that potent IL-12-inducing ability is conserved in strains of the $L$. casei group. In addition to the strains of the $L$. casei group, the 3 reference strains, as well as the type strain, of $L$. fermentum induced high levels of IL-12. All strains belonging to the other 6 species induced low levels of IL-12, as did the corresponding type strains. Most strains of these 6 species were sensitive to M-1 enzyme treatment.

The sensitivity of these Lactobacillus strains to M-1 enzyme and the ability of the strains to induce IL-12 are plotted in Figure 7. A statistically significant negative correlation ( $\mathrm{r}=-0.747, P<0.001$ ) was observed by Pearson's correlation coefficient test between sensitivity to M-1 enzyme and IL-12-inducing ability. These findings suggest that the resistance of lactobacilli to intracellular digestion is a very important factor in determining the ability to induce IL-12, although other unknown factors may also play a role.

\section{Loss of IL-12-Inducing Ability in LCS After Lysis of the Cell Wall}

Using LcS, we examined the involvement of cell wall structure in the induction of IL-12. Although LcS was resistant to treatment with lysozyme or a low dose of M-1 enzyme (Figure 5), previous studies showed that extended treatment with a high dose of M-1 enzyme could digest the cell wall of $\mathrm{LcS}$, resulting in the release of soluble PS-PG (Nagaoka et al., 1990). Thus, we treated LcS with $50 \mu \mathrm{g} / \mathrm{mL}$ of M-1 enzyme for 10 to 120 min, and the degree of digestion was evaluated both in terms of the decrease in OD600 and the reactivity to Giemsa staining. Optical density at $600 \mathrm{~nm}$ decreased according to the duration of treatment with a high dose of M-1 enzyme and resulted in $80 \%$ loss after $120 \mathrm{~min}$ of treatment (Figure 8A), and the reactivity to Giemsa stain was also reduced accordingly (Figure 8B). The pictures show the generation of protoplasts after lysis of the cell wall by M-1 enzyme. The IL-12-inducing ability of digested LcS was also examined. The IL-12inducing ability of LcS diminished according to the duration of treatment with the enzyme (Figure $8 \mathrm{C}$ ), indicating that the cell wall is essential for induction of IL-12.

\section{IL-12-Inducing Ability of Cell Wall Components of LCS}

To identify the cell wall components responsible for IL-12 induction, PS-PG and an insoluble cell wall prepa- 

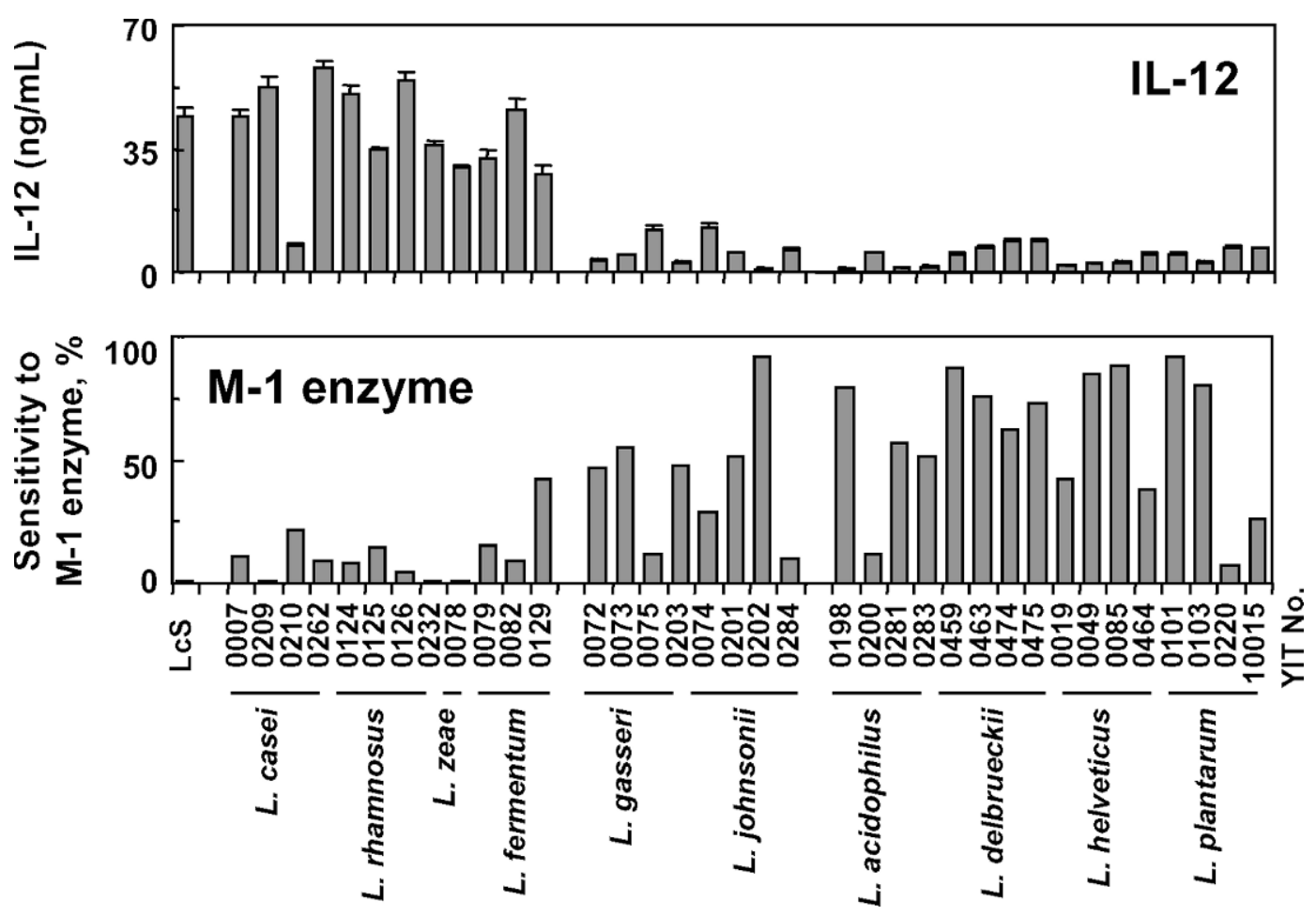

Figure 6. Interleukin-12-inducing ability and sensitivity to M-1 enzyme in reference strains of lactobacilli. (Top panel) Peritoneal macrophages were cultured with 36 Lactobacillus reference strains $(10 \mu \mathrm{g} / \mathrm{mL})$ for $24 \mathrm{~h}$, and the levels of IL-12 in culture supernatants were determined by ELISA. Data are means \pm SD of triplicate cultures. (Bottom panel) Lactobacillus strains were treated with M-1 enzyme $(10 \mu \mathrm{g} / \mathrm{mL})$ for $10 \mathrm{~min}$. The sensitivity of bacteria to M-1 enzyme was calculated as described in the Materials and Methods section. Data are means of 2 independent experiments. YIT = Yakult Institute, Tokyo (Tokyo, Japan).

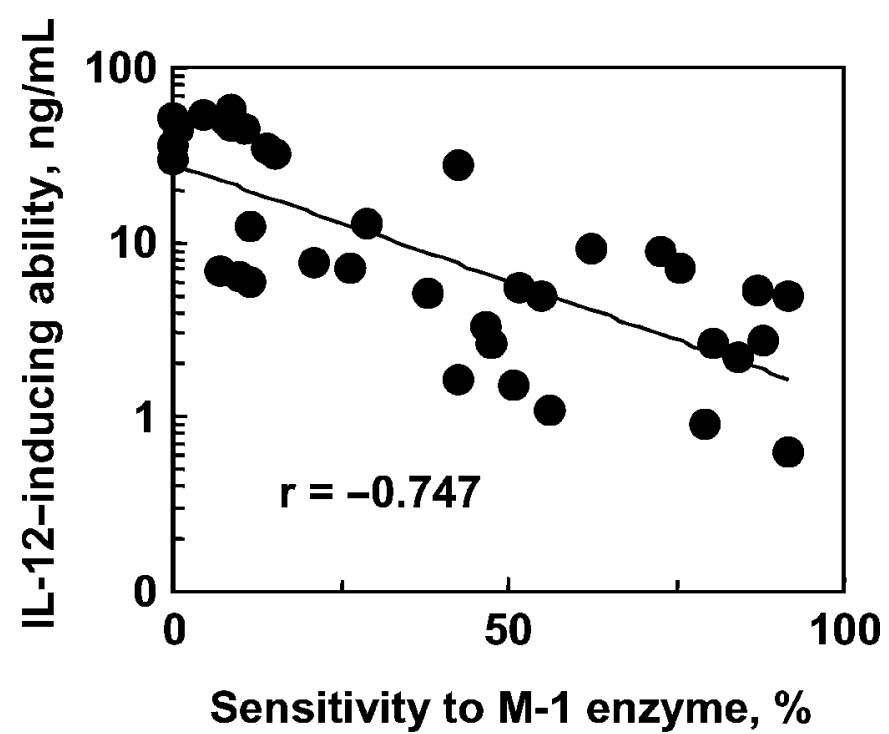

Figure 7. Negative correlation between the sensitivity of lactobacilli to in vitro $N$-acetylmuramidase treatment and IL-12-inducing ability. The sensitivity of 36 Lactobacillus reference strains to M-1 enzyme and the IL-12-inducing ability (the IL-12 level induced by $10 \mu \mathrm{g} / \mathrm{mL}$ bacteria in Figure 6) of these strains are plotted. The logarithmic curve and $\mathrm{r}$ value are shown. ration having an intact structure (ICW) were also prepared from LcS, and their ability was tested. As shown in Figure 9A, ICW, as well as whole LcS, could induce IL-12 effectively, but soluble PS-PG could not. Elimination of the polysaccharide moiety from ICW by hydrogen fluoride treatment resulted in the loss of IL-12-inducing ability. These results indicate the importance of an intact cell wall structure for LcS to induce IL-12.

\section{DISCUSSION}

Using mouse peritoneal macrophage cultures, 47 Lactobacillus strains belonging to 10 species were tested for the ability to induce IL-12. There were considerable differences in IL-12-inducing ability among the strains tested, and strains belonging to a single species exhibited similar IL-12-inducing abilities. Almost all strains belonging to the $L$. casei group could potently induce IL-12, and these results were consistent with previous observations showing that some specific strains belonging to the species of $L$. casei-L. paracase $i$ and L. rhamnosus were strong IL-12 inducers (Miettinen et al., 1998; Hessle et al., 1999; Christensen et al., 2002). These findings suggest that potent IL-12inducing ability may be conserved in certain species, 
A

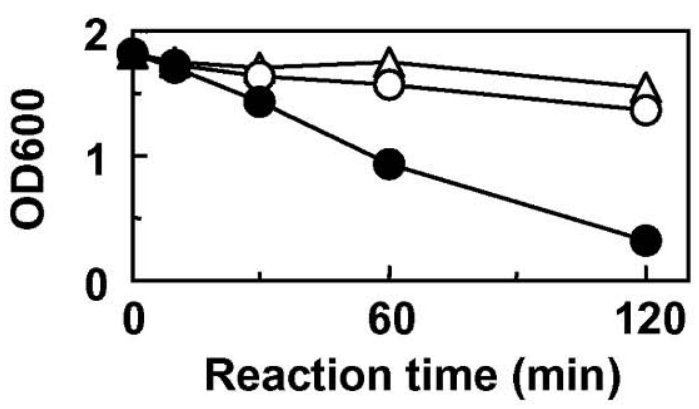

B
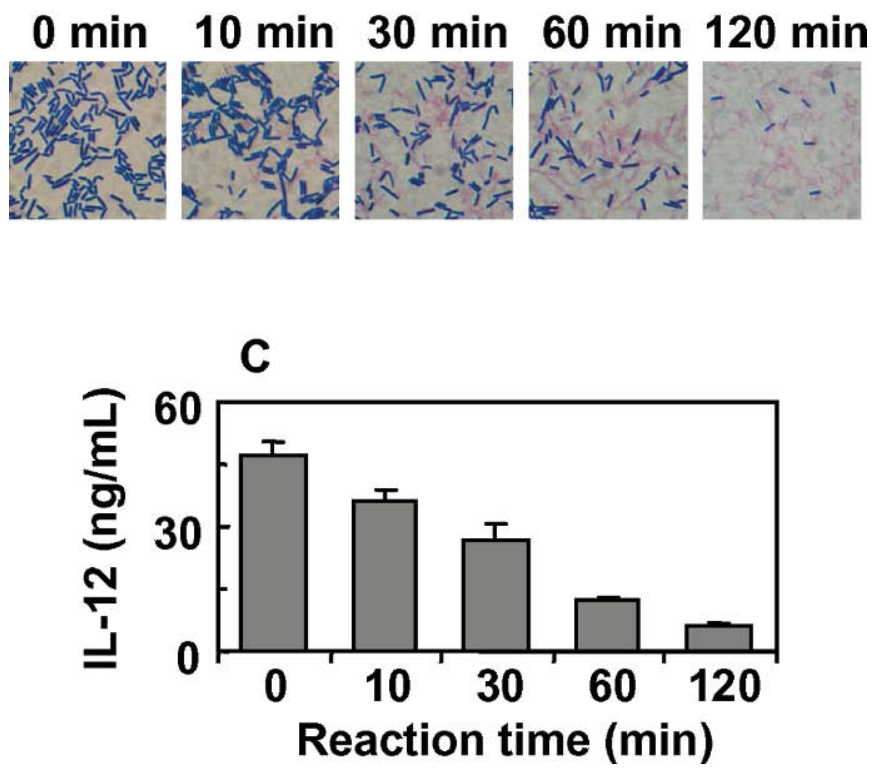

Figure 8. Importance of the cell wall in IL-12 induction by $L$. casei strain Shirota (LcS). Lactobacillus casei strain Shirota was treated with M-1 enzyme (10 $\mu \mathrm{g} / \mathrm{mL}$, open circles; $50 \mu \mathrm{g} / \mathrm{mL}$, closed circle) or lysozyme (50 $\mu \mathrm{g} / \mathrm{mL}$, open triangles) for $10,30,60$, and 120 min. (A) The extent of lysis of the cell wall was evaluated with a reduction of optical density at $600 \mathrm{~nm}$ (OD600). (B) Lactobacillus casei strain Shirota treated with $50 \mu \mathrm{g} / \mathrm{mL}$ of M-1 enzyme was stained with Giemsa. (C) Peritoneal macrophages were cultured with LcS $(10 \mu \mathrm{g} / \mathrm{mL})$ treated with $50 \mu \mathrm{g} / \mathrm{mL}$ of M-1 enzyme for $24 \mathrm{~h}$, and the levels of IL-12 in culture supernatants were determined by ELISA. Data are means \pm SD of triplicate cultures.

namely, the $L$. casei group, to slightly varying degrees among strains belonging to this group.

To characterize the properties important for the induction of IL-12, we examined the phagocytosis and lysis of lactobacilli by macrophages. The pattern of phagocytosis and lysis of lactobacilli could be divided into 3 groups: group $R$, in which bacteria were gradually phagocytosed and were not easily lysed; group $\mathrm{S}$, in which bacteria were rapidly phagocytosed and lysed;

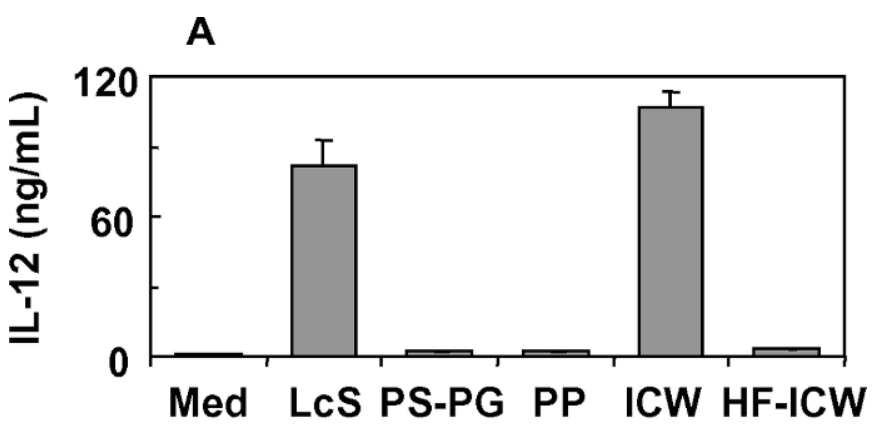

B

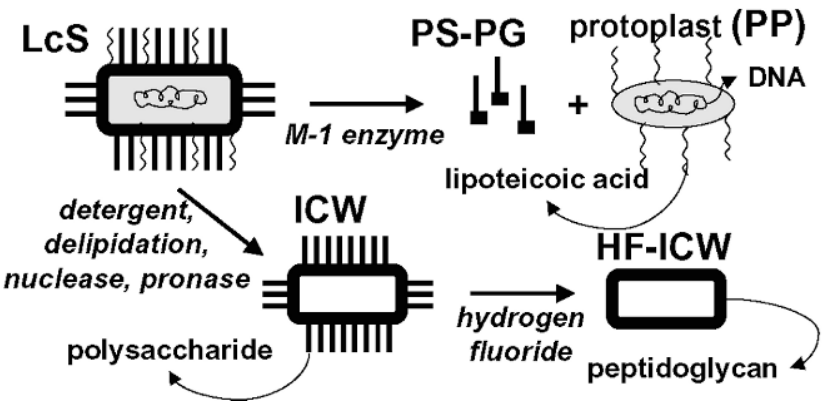

Figure 9. Effect of cell wall components prepared from $L$. casei strain Shirota (LcS) on IL-12 production. (A) Peritoneal macrophages were cultured with or without (Med) $10 \mu \mathrm{g} / \mathrm{mL}$ of LcS, polysaccharidepeptidoglycan complex (PS-PG), protoplast (PP), intact cell wall (ICW), or hydrogen fluoride-treated ICW (HF-ICW) for $24 \mathrm{~h}$, and the levels of IL-12 in culture supernatants were determined by ELISA. Data are means \pm SD of triplicate cultures. (B) Diagrams of the structure of cell wall components are shown.

and group I, in which bacteria were gradually phagocytosed and were easily lysed. Potent IL-12-inducing strains, such as LcS and the type strains of $L$. casei, $L$. rhamnosus, $L$. zeae, and $L$. fermentum, belonged to group R. A negative correlation was revealed between sensitivity of lactobacilli to in vitro digestion with M-1 enzyme and IL-12-inducing ability. In addition, the IL12-inducing ability of $\mathrm{LcS}$ was diminished by digestion of its cell wall. Taken together, these results demonstrate that phagocytosis of lactobacilli and their subsequent digestion are closely related to IL-12 induction, suggesting that the resistance of the cell wall to intracellular digestion is one of the critical factors in determining the ability of lactobacilli to induce IL- 12 .

Some strains were exceptions to the rule that Lactobacillus strains resistant to in vitro treatment with M1 enzyme have strong IL-12-inducing ability. Lactobacillus casei YIT 0210, L. gasseri YIT 0075, L. johnsonii YIT 0284, L. acidophilus YIT 0200, and L. plantarum YIT 0220 were relatively resistant to M-1 enzyme treatment but did not induce large amounts of IL-12 (Figure 
6). The following explanation is possible. These strains might have digested in the macrophages, although they were resistant to in vitro M-1 enzyme treatment, as shown in the type strain of $L$. gasseri (Figures 3,5 ). In contrast, L. fermentum YIT 0129 was relatively sensitive to M-1 enzyme treatment but could induce IL-12 effectively (Figure 6). Such an unusual strain may have cell components that can induce IL-12 production even after cell wall digestion within macrophages, or that might show different digestivity in macrophages from that toward M-1 enzyme treatment. Despite these exceptional cases, analyzing the sensitivity of Lactobacillus strains to M-1 enzyme treatment can be considered to provide valuable information on their IL-12-inducing ability.

Our findings can be considered to indicate that the host should activate the innate immune system to clear particular bacteria in the event of difficulty in digesting these bacteria within macrophages. That intracellular pathogenic bacteria such as Listeria monocytogenes induce IL-12 and activate the host immune system is well known (Trinchieri, 1994). These intracellular pathogens can escape from digestion, survive, and multiply in macrophages. On the other hand, lactic acid bacteria, including lactobacilli, are considered safe. Asahara et al. (2003) reported that live LcS, which differs from $L$. monocytogenes, showed a rapid decrease in viability after phagocytosis by macrophages, probably because of the activity of bactericidal nitric oxide. In addition, we confirmed that the LcS phagocytosed by macrophages was ultimately digested (data not shown). Considering these findings together with the long history of safe use of lactobacilli, it can be said that specific strains of lactobacilli are safe inducers of IL-12.

It is possible that the ability of bacteria to induce IL12 is due to the skeletal structure of the cell wall. The Lactobacillus cell wall skeleton has peptidoglycan as a major component, polysaccharide covalently bound to peptidoglycan, and lipoteichoic acid extending from the cell membrane (Figure 9B). The present study showed that the intact cell wall structure of $\mathrm{LcS}$ was important in inducing IL-12, and that soluble PS-PG released from the LcS cell wall by M-1 enzyme treatment could not induce IL-12. Yasutake et al. (1984) showed that the antitumor activity of LcS was reduced by digestion of the cell wall through treatment with M-1 enzyme. Sato et al. (1988) reported that a cell wall preparation from LcS or another strain of $L$. casei activated host resistance against listeria, but neither the polysaccharide fraction nor a polysaccharide-depleted peptidoglycan fraction prepared from the cell wall of these strains could effectively enhance anti-infectious activity. These observations are consistent with our results showing that an intact LcS cell wall structure is necessary to induce IL-12. Although the results presented by Sato et al. and by our group indicate the importance of the polysaccharide moiety in the cell wall, the role of the polysaccharide moiety in inducing IL-12 is still unclear. Regarding this issue, we would like to propose 2 possible explanations. One possibility is that the polysaccharide moiety is directly recognized by a corresponding receptor mediating a cytokine response. In this case, large numbers of polysaccharides may need to be present on a certain insoluble matrix such as the peptidoglycan polymer for effective induction of IL-12 (Dixon et al., 2001), because soluble PS-PG could not induce IL-12. Alternatively, the polysaccharide moiety may act indirectly on IL-12 induction by protecting the peptidoglycan structure from enzyme digestion. Zhang et al. (2001) proposed that the polysaccharide moiety of the bacterial cell wall may protect peptidoglycan from enzyme degradation, leading to inflammatory reactions. We also ascertained that polysaccharide-depleted ICW (HF-ICW) could be easily digested by treatment with $N$-acetylmuramidase (data not shown).

Toll-like receptors are considered key players in the induction of cytokines by microbes and microbial components, and TLR2 and TLR4 are likely to be involved in recognizing the bacterial cell wall components (Takeda and Akira, 2005). The experiments using macrophages deficient in TLR2, TLR4, or MyD88 indicated that MyD88-dependent signaling was indispensable for IL12 production induced by LcS, but neither TLR2 or TLR4 deficiency reduced IL-12 production. Both these TLR convey signals through MyD88 to produce cytokines, although TLR4 has another signaling pathway independent of MyD88. In recognizing LcS whole cells, stimulatory signals via 2 or more TLR recognizing cell components such as peptidoglycan and cell wall polysaccharides may lead to IL-12 secretion. Accordingly, because of redundancy of the signal via TLR2 and TLR4, our data do not exclude the possibility that TLR2 and TLR4 play a role in recognizing cell wall components of LcS. Alternatively, receptors other than TLR2 and TLR4 may be involved in inducing IL-12 in a MyD88-dependent manner. On the other hand, most studies examining the ligands and functions of TLR have been performed using various soluble cell components purified from bacterial cells, and the research on cell components responsible for IL-12 induction has been rather unsuccessful. Although some soluble bacterial components did induce IL-12, their ability to induce IL-12 was weaker than that of the intact bacterial cells (Cleveland et al., 1996; Huang et al., 1999; Hessle et al., 2000). Dixon et al. (2001) showed that lipopolysaccharide as a part of intact Neisseria meningitides, but not soluble lipopolysaccharide, can induce IL-12 effectively. Underhill et al. (1999) found that phagocytosis 
of bacteria by macrophages elicits recruitment of TLR2 to phagosomes to recognize bacterial components effectively. Furthermore, Uronen-Hansson et al. (2004) showed that effective induction of IL-12 required TLR2 and TLR4 within dendritic cells to recognize $N$. meningitides cells after phagocytosis. Our results also indicate that the insoluble ICW of LcS, but not the solubilized cell wall, could induce IL-12 and that the phagocytosing step is indispensable for IL-12 induction. Taken together, these findings could explain why soluble bacterial components show weaker induction of IL-12 than do intact bacterial cells.

Finally, this study demonstrates that particular strains of lactobacilli with resistance to digestion in macrophages can be potent inducers of IL-12. The findings not only provide valuable information on the bacterial characteristics necessary for effective induction of IL-12, but also propose a novel strategy for selecting new probiotic strains with the ability to augment innate immunity. Examining the sensitivity of Lactobacillus strains to $N$-acetylmuramidase can be useful for primary screening of IL-12-inducing strains. In fact, the well-known probiotic strain LcS is a potent IL-12 inducer with a rigid cell wall that is resistant to treatment with the enzyme. Interestingly, LcS was originally selected based on tolerance to gastric juices, bile acid, and intestinal digestive enzymes rather than on its immunostimulatory activity. The ability to survive gastrointestinal passage is considered to be a special feature of probiotic strains and may result from the rigid structure of the cell wall. If the probiotic feature of survival in the gut correlates with resistance to digestion in macrophages, it may be no wonder that some probiotic Lactobacillus strains are potent immunostimulators.

\section{CONCLUSIONS}

The intact cell wall structure is an important element in the ability of lactobacilli to induce IL-12, and the resistance of the cell wall to intracellular digestion is one of the critical factors in determining the IL-12inducing ability of lactobacilli. These findings not only provide important information on the bacterial characteristics necessary for effective induction of IL-12, but also present a novel strategy for selecting new immunostimulatory probiotic strains.

\section{ACKNOWLEDGMENTS}

We are grateful to Teruo Yokokura and Koji Nomoto for critical reading of the manuscript, and to Ikuo Kato and Shin-ichiro Shimada for valuable discussions. We also gratefully acknowledge the staff of the animal facility of the Yakult Central Institute for their expertise in breeding mice.

\section{REFERENCES}

Asahara, T., M. Takahashi, K. Nomoto, H. Takayama, M. Onoue, M. Morotomi, R. Tanaka, T. Yokokura, and N. Yamashita. 2003. Assessment of safety of Lactobacillus strains based on resistance to host innate defense mechanisms. Clin. Diagn. Lab. Immunol. 10:169-173.

Björkstén, B. 1999. The intrauterine and postnatal environments. J. Allergy Clin. Immunol. 104:1119-1127.

Christensen, H. R., H. Frøkiær, and J. J. Pestka. 2002. Lactobacilli differentially modulate expression of cytokines and maturation surface markers in murine dendritic cells. J. Immunol. 168:171-178.

Cleveland, M. G., J. D. Gorham, T. L. Murphy, E. Tuomanen, and K. M. Murphy. 1996. Lipoteicoic acid preparations of Gram-positive bacteria induce interleukin-12 through a CD14-dependent pathway. Infect. Immun. 64:1906-1912.

Dixon, G. L. J., P. J. Newton, B. M. Chain, D. Katz, S. R. Andersen, S. Wong, P. van der Ley, N. Klein, and R. E. Callard. 2001. Dendritic cell activation and cytokine production induced by group B Neisseria meningitidis: Interleukin-12 production depends on lipopolysaccharide expression in intact bacteria. Infect. Immun. 69:4351-4357.

Dugas, B., A. Mercenier, I. Lenoir-Wijnkoop, C. Arnaud, N. Dugas, and E. Postaire. 1999. Immunity and probiotics. Immunol. Today 20:387-390.

Halpern, M. D., R. J. Kurlander, and D. S. Pisetsky. 1996. Bacterial DNA induces murine interferon- $\gamma$ production by stimulation of interleukin-12 and tumor necrosis factor- $\alpha$. Cell. Immunol. 167:72-78.

Hessle, C., B. Andersson, and A. E. Word. 2000. Gram-positive bacteria are potent inducers of monocytic interleukin-12 (IL-12) while Gram-negative bacteria preferentially stimulate IL-10 production. Infect. Immun. 68:3581-3586.

Hessle, C., L. A. Hanson, and A. E. Wold. 1999. Lactobacilli from human gastrointestinal mucosa are strong stimulators of IL-12 production. Clin. Exp. Immunol. 116:276-282.

Huang, L.-Y., A. M. Krieg, N. Eller, and D. E. Scott. 1999. Induction and regulation of Th1-inducing cytokines by bacterial DNA, lipopolysaccharide, and heat-inactivated bacteria. Infect. Immun. 67:6257-6263.

Kalliomäki, M. A., and E. Isolauri. 2004. Probiotics and down-regulation of the allergic response. Immunol. Allergy Clin. N. Am. 24:739-752.

Kato, I. 2000. Antitumour activity of lactic acid bacteria. Pages 115138 in Probiotics 3. R. Fullar and G. Perdigon, ed. Kluwer Academic Publishers, Dordrecht, The Netherlands.

Matsuguchi, T., A. Takagi, T. Matsuzaki, M. Nagaoka, K. Ishikawa, T. Yokokura, and Y. Yoshikai. 2003. Lipoteicoic acid from Lactobacillus strains elicit strong tumor necrosis factor $\alpha$-inducing activities in macrophages through Toll-like receptor 2. Clin. Diag. Lab. Immunol. 10:259-266.

Miettinen, M., S. Matikainen, J. Vuopio-Varkika, J. Pirhonen, K. Varkila, M. Kurimoto, and I. Julkunen. 1998. Lactobacilli and streptococci induce interleukin-12 (IL-12), IL-18, and $\gamma$ interferon production in human peripheral blood mononuclear cells. Infect. Immun. 66:6058-6062.

Mort, J. M., and D. T. A. Lamport. 1977. Anhydrous hydrogen fluoride deglycosylates glycoproteins. Anal. Biochem. 82:289-309.

Nagaoka, M., M. Muto, K. Nomoto, T. Matsuzaki, T. Watanabe, and T. Yokokura. 1990. Structure of polysaccharide-peptidoglycan complex from the cell wall of Lactobacillus casei YIT 9018. J. Biochem. (Tokyo) 108:568-571.

Perdigón, G., R. Fuller, and R. Raya. 2001. Lactic acid bacteria and their effect on the immune system. Curr. Issues Intest. Microbiol. $2: 27-42$.

Reid, G., J. Jass, M. T. Sebulsky, and J. K. McCormick. 2003. Potential uses of probiotics in clinical practice. Clin. Microb. Rev. 16:658-672.

Salkowski, C. A., G. R. Detore, and S. N. Vogel. 1997. Lipopolysaccharide and monophosphoryl lipid A differentially regulate interleu- 
kin-12, $\gamma$ interferon, and interleukin-10 mRNA production in murine macrophages. Infect. Immun. 65:3239-3247.

Salminen, S., C. Bouley, M.-C. Boutron-Ruault, J. H. Cummings, A. Franck, G. R. Gibson, E. Isolauri, M.-C. Moreau, M. Roberfroid, and I. Rowland. 1998. Functional food science and gastrointestinal physiology and function. Br. J. Nutr. 80:S147-S171.

Sato, K., H. Saito, H. Tomioka, and T. Yokokura. 1988. Enhancement of host resistance against Listeria infection by Lactobacillus caesi: Efficacy of cell wall preparation of Lactobacillus casei. Microbiol. Immunol. 32:1189-1200.

Shibata, Y. 1995. Prostaglandin E2 release triggered by phagocytosis of latex particles. J. Immunol. 154:2878-2887.

Shida, K., K. Makino, A. Morishita, K. Takamizawa, S. Hachimura, A. Ametani, T. Sato, Y. Kumagai, S. Habu, and S. Kaminogawa. 1998. Lactobacillus casei inhibits antigen-induced IgE secretion through regulation of cytokine production in murine splenocyte cultures. Int. Arch. Allergy Immunol. 115:278-287.

Shida, K., R. Takahashi, E. Iwadate, K. Takamizawa, H. Yasui, T. Sato, S. Habu, S. Hachimura, and S. Kaminogawa. 2002. Lactobacillus casei strain Shirota suppresses serum immunoglobulin E and immunoglobulin G1 responses and systemic anaphylaxis in a food allergy model. Clin. Exp. Allergy 32:563-570.

Takeda, K., and S. Akira. 2005. Toll-like receptors in innate immunity. Int. Immunol. 17:1-14.

Thoma-Uszynski, S., S. M. Kiertscher, M. T. Ochoa, D. A. Bouis, M. V. Norgard, K. Miyake, P. J. Godowski, M. D. Roth, and R. L. Modlin. 2000. Activation of Toll-like receptor 2 an human dendritic cells triggers induction of IL-12, but not IL-10. J. Immunol. 165:3804-3810.
Trinchieri, G. 1994. Interleukin-12: A cytokine produced by antigenpresenting cells with immunoregulatory functions in the generation of T-helper cells type 1 and cytotoxic lymphocytes. Blood 84:4008-4027.

Underhill, D. M., A. Ozinsky, A. M. Hajjar, A. Stevens, C. B. Wilson, M. Bassetti, and A. Aderem. 1999. The Toll-like receptor 2 is recruited to macrophage phagosomes and discriminates between pathogens. Nature 401:811-815.

Uronen-Hansson, H., J. Allen, M. Osman, G. Squires, N. Klein, and R. E. Callard. 2004. Toll-like receptor 2 (TLR2) and TLR4 are present inside human dendritic cells, associated with microtubules and the Golgi apparatus but are not detectable on the cell surface: Integrity of microtubules is required for interleukin-12 production in response to internalized bacteria. Immunology 111:173-178.

Yasutake, N., T. Matsuzaki, K. Kimura, S. Hashimoto, T. Yokokura, and Y. Yoshikai. 1999. The role of tumor necrosis factor (TNF)$\alpha$ in the antitumor effect of intrapleural injection of Lactobacillus casei strain Shirota in mice. Med. Microbiol. Immunol. (Berlin) 188:9-14.

Yasutake, N., M. Ohwaki, T. Yokokura, and M. Mutai. 1984. Comparison of antitumor activity of Lactobacillus casei with other bacterial immunopotentiators. Med. Microbiol. Immunol. (Berl.) 173:113-125.

Yoshida, A., and Y. Koide. 1997. Arabinofuranosyl-terminated and mannosylated lipoarabinomannans from Mycobacterium tuberculosis induce different levels of interleukin-12 expression in murine macrophages. Infect. Immun. 65:1953-1955.

Zhang, X., M. Rimpiläinen, E. Šimelyte, and P. Toivanen. 2001. Characterisation of Eubacterium cell wall: Peptidoglycan structure determines arthritogenicity. Ann. Rheum. Dis. 60:269-274. 